\title{
Event-Free Survival
}

National Cancer Institute

\section{Source}

National Cancer Institute. Event-Free Survival. NCI Thesaurus. Code C96340.

The length of time after treatment during which a patient survives with no sign of a particular complication of disease. 